\title{
Warehouse Capacities in the Pharmaceutical Industry - Plan or Outsource?
}

\author{
Felix Friemann*, Manuel Rippel, and Paul Schönsleben \\ ETH Zürich, BWI Center for Industrial Management, \\ WEINBERGSTRASSE 56, 8092 ZÜRICH, Switzerland \\ \{ffriemann, mrippel, pschoensleben\} @ethz.ch
}

\begin{abstract}
The pharmaceutical industry is undergoing a change. Different future developments such as the increasing amount of biopharmaceutical products and even stricter regulations increase the need for a reliable long range warehouse capacity planning. Results from a literature analysis indicate that managing these operations will mainly remain the responsibility of the pharmaceutical company itself and may not be outsourced. Hence, the capabilities must be built up within the pharmaceutical companies itself, too. However, none of the models identified in the literature can fulfill all requirements of a reliable and detailed long-range planning process in the pharmaceutical industry. Providing suggestions for further research areas, the paper contributes to the further development of more reliable planning processes.
\end{abstract}

Keywords: Supply Chain Management, Pharmaceutical Industry, Long-Range Warehouse Capacity, Strategic Planning, Outsourcing.

\section{Introduction}

Global medicines spendings will increase from $\$ 965 \mathrm{Bn}$ in 2012 to $\$ 1 \mathrm{Tn}$ in 2014 and exceed $\$ 1.17$ Tn by 2017 according to IMS Health showing the size of the pharmaceutical industry [1]. The industry can be divided into the market segments of ethical (prescription) and "over-the-counter" products [2]. This paper focuses on researching pharmaceutical companies (RPC) which are making most of their revenue from ethical products.

Due to various future trends, supply chain managers in this industry will increasingly face challenges: The market of biologics (complex macromolecules with some form of polymer structure) will grow above average and amount to approx. $19-20 \%$ of the overall pharmaceutical market in 2017 [1]. These products are generally more sensitive to environmental changes (e.g. temperature) on transports and in the warehouse than traditional solid products (e.g. tablets). With the BRIC markets (Brazil, Russia, India, China) being key growth drivers, these capacities are needed at different locations than before, in sometimes challenging settings [3]. All this has to be done under the umbrella of the highly regulated pharmaceutical industry where most

\footnotetext{
* Corresponding author.

B. Grabot et al. (Eds.): APMS 2014, Part I, IFIP AICT 438, pp. 427 434, 2014.

(C) IFIP International Federation for Information Processing 2014
} 
process changes require new approvals of different authorities and warehouse security (anti-counterfeiting) is becoming more and more important [4]. The new European "Guidelines of 7 March 2013 on Good Distribution Practice of Medicinal Products for Human Use (2013/C 68/01)" further increase the requirements for qualification, temperature control and traceability in the distribution [5].

Increasing supply chain transparency by better monitoring warehouse capacities and their development in the long-term seems one answer to better cope with these challenges. Expert interviews indicated that several pharmaceutical companies lack this capability. To exploit the reasons of this discrepancy, this paper firstly analyzes whether there can be a trend identified that capacities are outsourced and, consequently, warehouse planning will not be an issue anymore in the future. This is reviewed in a semi-structured interview series within 11 out of the 2012 TOP20 pharmaceutical companies (according to revenue) [6]. Secondly, the paper summarizes the findings of a literature analysis identifying relevant planning processes and models in academic publications.

\section{Methodology}

Originating from a case study with supply chain experts of a leading pharmaceutical company, different alternatives to increase transparency for warehouse capacities were evaluated. A basic question that arose was whether the company should estimate capacities on its own or whether the general trend is to outsource it in the industry. The derived hypothesis was that companies outsourcing this task to logistics providers face less limitations with regards to warehouse capacities. To answer this, a semistructured interview series with supply chain managers from 11 out of the 2012 TOP20 researching pharmaceutical companies was used [6]. The interview guideline used contained both qualitative and quantitative questions. The interviews were conducted between 04'13 - 05'13. All interviewees were senior managers in a Supply Chain Management position. For reasons of validation, the survey results were sent to all participants with the request of approval. All results were approved. If a company differentiates between business units (animal health, generics branch, etc.), our study focused on the research-oriented pharmaceutical branch whenever possible to ensure comparability of the answers.

Secondly, to answer the question whether good models and practices exist to plan warehouse capacities in the pharmaceutical industry, the state-of-the-art is evaluated by a literature analysis. Scopus (www.scopus.com) was used as the main database. The findings of this literature search were further analyzed using scientometrics ([7], see [8] for an application example).

\section{Pharmaceutical Supply Chains}

The American Production and Inventory Control Society (APICS) define supply chain management as the design, planning, execution, control, and monitoring of supply chain activities with the objective of creating net value, building a competitive 
infrastructure, leveraging world-wide logistics, synchronizing supply with demand, and measuring performance globally [9].

Drug development can take around 15 years before it comes to the market. These phases can be divided into discovery-phase, clinical (exploratory) and registration (full development) phase ([2]). The earlier the stage in the drug development process, the bigger the uncertainty for a supply chain manager on whether to consider this product in the corresponding long-range capacities (i.e. how probable it is that it passes on to the next stage) and which logistics requirements this drug will actually have (i.e. temperature range, volume, special characteristics).

Within the product life cycle of a drug, the development phase is followed by an introductory, growth, maturity and decline stage. Production / capacity planning and inventory management becomes especially important in the growth and maturity stage [10] as products at these stages consume most of the warehouse capacities.

The general pharmaceutical manufacturing supply chain (Fig. 1) consists of the stages primary manufacturing where the active pharmaceutical ingredient (API) is produced, secondary manufacturing formulating the drug (e.g. producing a tablet), 3) packaging and 4) finished product distribution [11]. These stages are globally distributed.

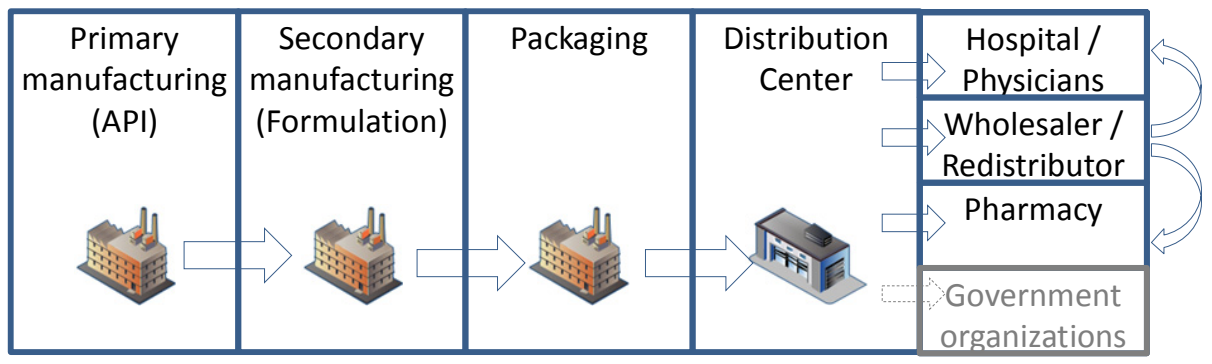

Fig. 1. General pharmaceutical supply chain structure (material flow)

\section{Outsourcing at Research-Focused Pharmaceutical Companies}

Interviews with experts of one case study company in a TOP5 researching pharmaceutical company ([6]) indicated that no high-level process is in place to monitor global warehouse capacities. Limitations happened in the past and are expected to increase in future due to previously mentioned developments. One argument not to spend resources on capacity planning might be that the operations tend to be further outsourced in future. Outsourcing means that parts of the value-added chain are turned over to other companies [12].

Fig. 2 illustrates the results of a semi-structured interview series with 11 out of the TOP20 pharmaceutical companies. It shows the mentioned level of outsourced activities (in percent and in terms of volume) throughout the supply chain indicated by the interviewees. It also expresses whether this percentage is expected to change in future (absolute value indicated by the black arrows). 


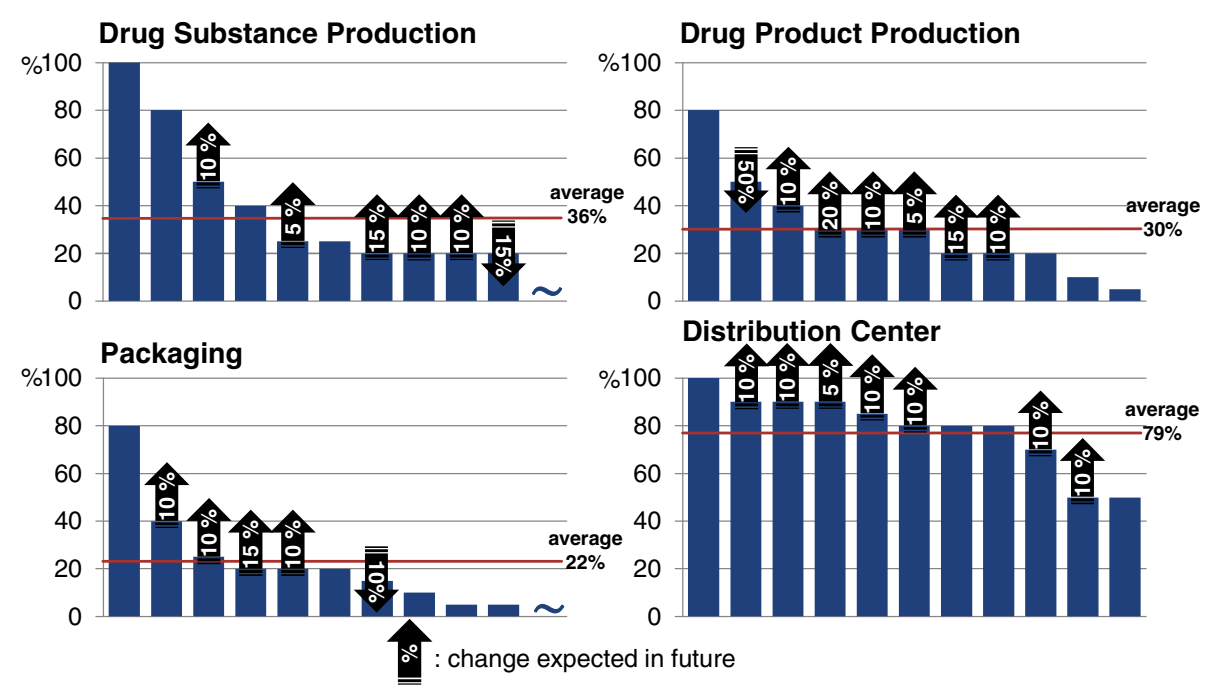

Fig. 2. Percentage of outsourced operations in the various stages of the Supply Chain and future change in percentage points (in terms of volume)

As one can notice, nowadays especially distribution centers are mostly outsourced (79\% on average). Here the trend is to outsource even more. At the other stages of the supply chain, the level of outsourcing is generally lower. Outsourcing in general is expected to increase throughout all stages of the Supply Chain.

One hypothesis to check was especially whether companies with higher percentages of outsourced operations encountered less warehouse capacity limitations in the past. The underlying reason is that logistics providers with greater process knowledge and multiple customers are able to better balance warehouse utilization and therefore encounter fewer limitations. But, as the interview results show, most limitations (e.g. not enough capacity available when needed) occur at the distribution centers. Hence, the hypothesis cannot be confirmed. The explanation can be manifold. One reason might be that there are different characteristics in the pharmaceutical industry (long lead times, high equipment costs and corresponding high utilization) that make planning difficult downstream the supply chain.

The degree of outsourcing within the packaging stage seems to be the lowest. Reasons for this might be the complexity e.g. with regards to product variety or counterfeiting risks at this stage. Anti-counterfeiting is still a very important topic in the industry.

As outsourcing reasons, the most common answers were 1) strategic decision - decide based on strategic importance of the product, 2) not core competence - outsource when the operation is not a core competence, 3) risk mitigation - outsource production and distribution to ensure supply and increase flexibility, 4) external know-how outsource when internal competence is not available.

Overall, it can be stated that even though outsourcing seems to generally increase, it will still be on a comparably low level at the production facilities from drug 
substance production until packaging making it necessary for pharmaceutical companies to establish a reliable process in order to estimate the required warehouse capacities and therefore ensure supply chain reliability. At a next step, the literature is analyzed for corresponding processes and models to help the pharmaceutical industry in this matter.

\section{$5 \quad$ Warehouse Capacity Planning in the Pharmaceutical Industry}

To identify streams and applicable literature in the field of warehouse capacity planning, keyword combinations 1) "supply chain", 2) "supply chain" AND "capacity", 3) "supply chain" AND "planning" and 4) "warehouse" AND "planning" were used in the Scopus database. Whether or not pharmaceutical supply chains should be treated with different tools than other industries is discussed in a controversial manner. Nevertheless, one can acknowledge that the pharmaceutical supply chain is more regulated than any other industrial sector and decisions can become ethical if a failure of the supply chain may have a severe impact on patients' lives, especially when dealing with ethical (prescribed) medicines like in this paper [2]. This imposes specific requirements on pharmaceutical supply chain planning. To identify the documents mentioning pharmaceutical issues, the keyword "pharmaceutical" was added to the previous keyword combinations. The number of results and especially the relation between general and pharmaceutical-specific literature is illustrated in Fig. 3.

The primary $y$-axis ( $n=1$ to 6000$)$ with the corresponding dotted lines show the results of a generic keyword search. The secondary $y$-axis $(n=1$ to 90$)$ with the corresponding continuous lines show the same keyword search limited to papers mentioning the pharmaceutical industry.

A first interesting finding is that the relation between general literature and literature mentioning pharmaceutical keywords is more or less continuously around $1.5 \%$ $(1.6 \%, 1.3 \%, 1.5 \%$ resp. $0.9 \%$ for the keyword searches mentioned before) over the given timeframe. Some literature is stating that many papers concentrate on a handful of industry sectors, automobile being among them [13]. So repeating the keyword search for the automotive sector, using "automotive" instead of "pharmaceutical" as a keyword, doubles the overall number of papers found (factor 2.0 - 2.5 for all keyword combinations compared to the previous search). It leaves the conclusion, that pharmaceutical supply chain planning tends indeed to be underrepresented compared to other industries. The reasons for this were not further analyzed and might be a good area for further research.

When analyzing collaboration of authors in the pharmaceutical field using the scientometrics method ([7]), the area seems rather fragmented. Two groups identified are L. Patrono, Mainetti, De Blasi et al. publishing about RFID-tracking in the pharmaceutical supply chain or Westenberger, Buhse et al. dealing with quality monitoring throughout the supply chain ([14], [15]). 


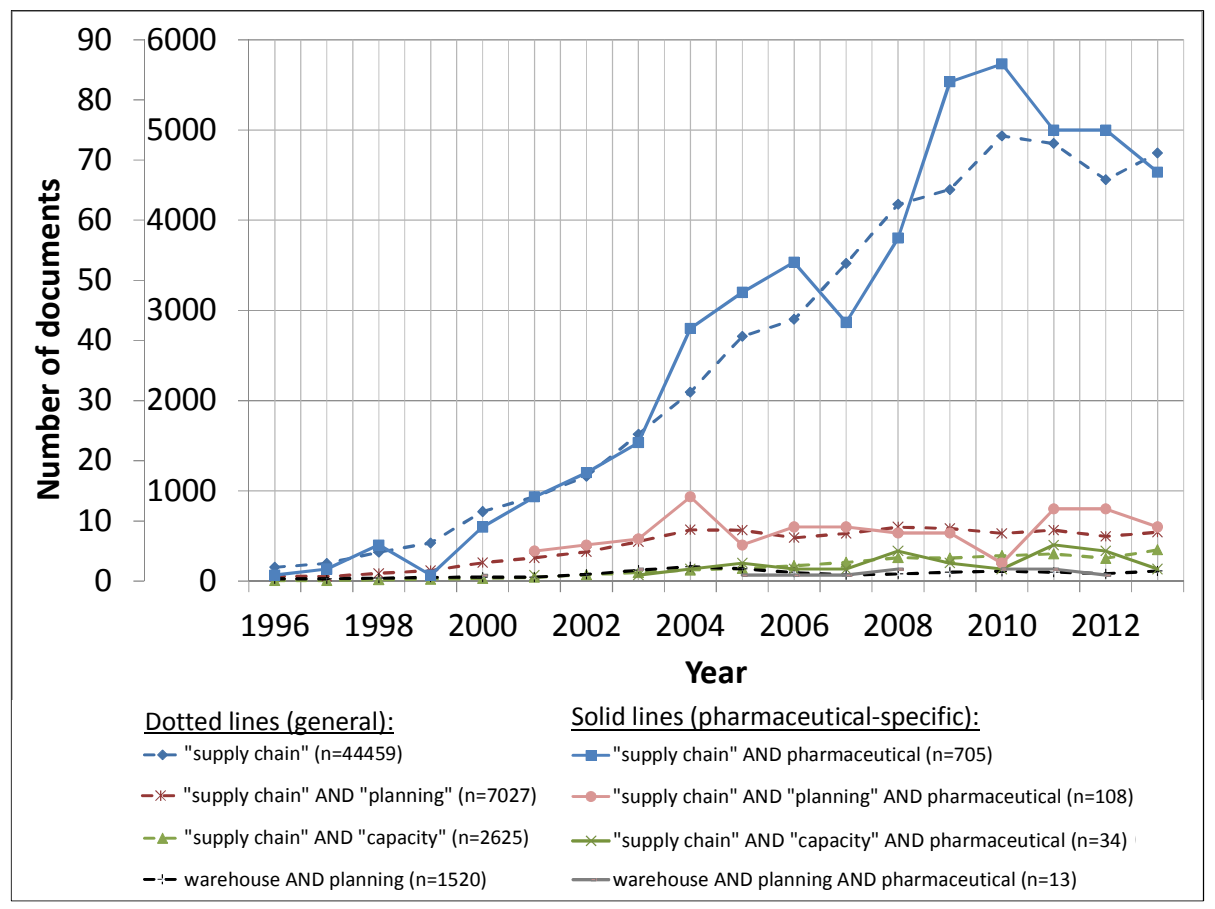

Fig. 3. Keyword search, timeframe 1990 - 2013 (shown: 1996-2013). Source scopus.com/. Updated: 04/2014

From the above streams, exemplary papers can be highlighted that deal with capacity planning in the context of supply chain managament. Gu et al. provide an extensive literature analysis with regards to warehouse operation planning whereas they do not discuss the global context within supply chain planning [16]. Heragu et al. discuss intrawarehouse improvements of the functional areas and propose an algorithm [17]. Susarla et al. or Levis et al. discuss integrated planning for a globally operating pharmaceutical companies, not considering warehouse requirements specifically though [18], [19]. Chen et al. discuss a simulation-optimization of the clinical trial supply chain [20]. Aghezzaf generally discusses strategic capacity and warehouse location planning including uncertainty and proposes a model [21]. For production capacity planning, several models exist. A profound general overview is provided by Mula et al. [22].

However, literature dealing with warehouse capacity planning in the context of a global supply chain and specifically fulfilling the requirements of pharmaceutical capacity planning (e.g. pallet spaces within different temperature zones) could not be identified by the literature research.

\section{Discussion and Conclusion}

This paper has introduced the reasons why warehouse capacity planning in the pharmaceutical industry will gain relevance in the future. The main production steps are 
still performed in-house at the interviewed pharmaceutical companies and this will stay mainly in-house in the future. Different developments will make it more difficult for supply chain managers to correctly plan the warehouse capacities in the longrange in order to get the right products to the right place in the right condition. With emerging markets getting more and more important in future, warehouse capacities will get even more difficult to correctly estimate.

Analyzing the current literature, this paper states that specific, highly automatable, readily applicable models for long-term warehouse capacity planning in the pharmaceutical industry could not be identified.

Further research has to be done in specifying requirements of such a model in the pharmaceutical industry, analyzing in greater detail how warehouse capacity planning is done in other industries and whether this can be leveraged for the pharmaceutical industry.

\section{References}

1. IMS Institute for Healthcare Informatics, The Global Use of Medicines: Outlook through 2017 (2013)

2. Savage, C.J., Roberts, K.J., Wang, X.Z.: A Holistic Analysis of Pharmaceutical Manufacturing and Distribution: Are Conventional Supply Chain Techniques Appropriate? Pharm. Eng. 26(4), 1-8 (2006)

3. Altmann, T., Werner, K.: Die Entwicklung des internationalen Pharmamarktes. Pharm. Ind. 75(9), 1418-1421 (2013)

4. Efrati, A., Loftus, P.: Lilly Drugs Stolen in Warehouse Heist. The Wall Street Journal (March 17, 2010)

5. Sponheimer, A.: Supply-Chain-Trends und Regularien in der Pharmalogistik. Pharm. Ind. 75(9), 1422-1428 (2013)

6. IMS Health: IMS Health, IMS MIDAS, Top 20 global corporations 2012 (2013)

7. Sci2 Team: Science of Science (Sci2) Tool. Indiana University and SciTech Strategies (2009)

8. Gram, M.: Equipment efficiency metrics in production systems. A literature review and survey. In: Book of proceedings of 9th International May Concefernce on Strategic Management - IMKSM 2013, pp. 468-478 (May 2013)

9. APICS - The Association for Operations Management, APICS Dictionary 13th edn. American Production \& Inventory Control Society, Incorporated, Chicago (2010)

10. Laínez, J.M., Schaefer, E., Reklaitis, G.V., Lainez, J.M.: Challenges and opportunities in enterprise-wide optimization in the pharmaceutical industry. Comput. Chem. Eng. 47, 1928 (2012)

11. Friemann, F., Verhasselt, S.: Best Practices for Supply Chain Management Techniques and Concepts across Industries. In: POMS 23rd Annual Conference, p. 16 (2012)

12. Schönsleben, P.: Integral Logistics Management, 4th edn., vol. 15(3), p. 1040. Auerbach Publications (2011)

13. Burgess, K., Singh, P.J., Koroglu, R.: Supply chain management: a structured literature review and implications for future research. Int. J. Oper. Prod. Manag. 26(7), 703-729 (2006) 
14. Keire, D.A., Ye, H., Trehy, M.L., Ye, W., Kolinski, R.E., Westenberger, B.J., Buhse, L.F., Nasr, M., Al-Hakim, A.: Characterization of currently marketed heparin products: key tests for quality assurance. Anal. Bioanal. Chem. 399(2), 581-591 (2011)

15. Kauffman, J.F., Gryniewicz-Ruzicka, C.M., Arzhantsev, D.J.D., Spencer, S.J.A., Wolfgang, X., Li, S., Pelster, L.N., Westenberger, B.J., Buhse, L.F.: Pharmaceutical surveillance with rapid spectroscopic screening technologies. Am. Pharm. Rev. 13(1), 58-62 (2010)

16. Gu, J., Goetschalckx, M., McGinnis, L.F.: Research on warehouse operation: A comprehensive review. Eur. J. Oper. Res. 177(1), 1-21 (2007)

17. Heragu, S.S., Du, L., Mantel, R.J., Schuur, P.C.: Mathematical model for warehouse design and product allocation. Int. J. Prod. Res. 43(2), 327-338 (2005)

18. Susarla, N., Karimi, I.A.A.: Integrated supply chain planning for multinational pharmaceutical enterprises. Comput. Chem. Eng. 42, 168-177 (2012)

19. Levis, A.A., Papageorgiou, L.G.: A hierarchical solution approach for multi-site capacity planning under uncertainty in the pharmaceutical industry. Comput. Chem. Eng. 28(5), 707-725 (2004)

20. Chen, Y., Mockus, L., Orcun, S., Reklaitis, G.V.: Simulation-optimization approach to clinical trial supply chain management with demand scenario forecast. Comput. Chem. Eng. 40, 82-96 (2012)

21. Aghezzaf, E.: Capacity planning and warehouse location in supply chains with uncertain demands. J. Oper. Res. Soc. 56(4), 453-462 (2004)

22. Mula, J., Poler, R., García-Sabater, J.P., Lario, F.C.: Models for production planning under uncertainty: A review. Int. J. Prod. Econ. 103(1), 271-285 (2006) 